\title{
Inspiratory drive is related to dynamic pulmonary hyperinflation in COPD patients
}

This article was published in the following Dove Press journal:

International Journal of COPD

27 March 2013

Number of times this article has been viewed

\section{Diego Gatta'}

Marco Fredi²

Giovanni Aliprandi²

Laura Pini'

\section{Claudio Tantucci'}

'Respiratory Medicine Unit, Department of Medical and Surgical Sciences, University of Brescia, Brescia, Italy; ${ }^{2}$ Respiratory Rehabilitation Unit, Hospital Domus Salutis, Brescia, Italy
Correspondence: Claudio Tantucci Medicina Interna I, University of Brescia, Spedali Civili di Brescia P.zzale Spedali Civili, I 25 I23 Brescia, Italy

Tel +39030398069

$\mathrm{Fax}+39030398069$

Email tantucci@med.unibs.it
Background: Baseline high neuromuscular drive is present in chronic obstructive pulmonary disease (COPD). In moderate-to-very severe COPD patients, both static and/or dynamic pulmonary hyperinflation have been demonstrated at rest.

Aim: To assess the influence of dynamic hyperinflation on neuromuscular drive at rest.

Methods: We recruited 22 patients with severe-to-very severe COPD showing resting dynamic pulmonary hyperinflation, as assessed by the baseline reduction of inspiratory capacity (IC) ( $<80 \%$ of predicted). IC, occlusion pressure $\left(\mathrm{P}_{0.1}\right)$, maximal inspiratory pressure (MIP), and their ratio were measured at end-expiratory lung volume (EELV) before and after acute inhalation of $400 \mathrm{mcg}$ of albuterol (metered-dose inhaler plus spacer). In these patients the bronchodilator response was assessed also as lung volume changes.

Results: Only in COPD patients with a marked increase in IC ( $>12 \%$ of baseline and at least $200 \mathrm{~mL}$ ) after bronchodilator, resting $\mathrm{P}_{0.1}$ showed a clinically significant decrease, despite the EELV diminution $(P<0.001)$. MIP was augmented following EELV reduction and therefore the $\mathrm{P}_{0.1} / \mathrm{MIP}$ ratio was markedly decreased $(P<0.001)$. In contrast, no changes in these indices were found after bronchodilator in COPD patients with insignificant variations of IC. Breathing pattern parameters did not vary in both sub-groups after albuterol.

Conclusion: Following bronchodilator, significant $\mathrm{P}_{0.1}$ decrease, MIP increase, and reduction of the $\mathrm{P}_{0.1} / \mathrm{MIP}$ ratio were found only in COPD patients with a marked IC increase and these changes were closely related. These findings suggest that bronchodilators, by decreasing dynamic hyperinflation, may control exertional and/or chronic dyspnea partly through a reduction of central neuromuscular drive.

Keywords: chronic obstructive pulmonary disease, control of breathing, inspiratory muscles, dynamic hyperinflation, bronchodilators

\section{Introduction}

In patients with moderate-to-severe chronic obstructive pulmonary disease (COPD), parameters reflecting static and dynamic pulmonary hyperinflation (DH) such as endexpiratory lung volume (EELV) or inspiratory capacity (IC) correlate better than forced expiratory volume in 1 second $\left(\mathrm{FEV}_{1}\right)$ with chronic dyspnea, ${ }^{1}$ and progressive $\mathrm{DH}$ is thought to be the main limiting factor of their exercise capacity because of related intolerable breathlessness. ${ }^{2,3}$ In COPD patients, the occurrence of $\mathrm{DH}$, either at rest or during exercise, is thought to induce dyspnea mainly by causing neuromechanical (or neuroventilatory) dissociation. ${ }^{3}$ However, a high inspiratory drive that is widely documented in severe-to-very severe $\mathrm{COPD}^{5}$ might also contribute to increased dyspnea in these patients. 
By increasing the expiratory flow reserve at low lung volumes, bronchodilators can reduce chronic and exertional dyspnea essentially by decreasing baseline EELV (or increasing IC) in moderate-to-severe COPD patients ${ }^{6-8}$ with $\mathrm{DH}$, and better neuromechanical coupling is believed to be responsible to a large extent for such improvement. ${ }^{9}$

The aim of the study was to assess whether the acute reduction of resting $\mathrm{DH}$ possibly obtained by bronchodilator administration could influence the neuromuscular inspiratory drive and its ratio with the inspiratory muscles' strength in stable COPD patients with marked airflow obstruction.

\section{Methods}

We prospectively evaluated a cohort of stable severe to very severe COPD outpatients with baseline IC values less than $80 \%$ of their predicted values, consecutively enrolled at the Respiratory Rehabilitation Unit, Hospital Domus Salutis, Brescia, Italy. The diagnosis of COPD was made according to the following criteria: (1) smoking history of more than 20 pack-years and/or the presence of other known risk factors for COPD; (2) baseline $\mathrm{FEV}_{1} /$ vital capacity ratio less than the 5 th percentile of normal limits; ${ }^{10}$ (3) increase of $\mathrm{FEV}_{1}$ less than $10 \%$ of the predicted value and less than $200 \mathrm{~mL}$ in absolute value after $400 \mathrm{mcg}$ of inhaled albuterol (metered-dose inhaler plus spacer); (4) no history or evidence of other diseases with chronic airflow obstruction such as chronic asthma, bronchiectasis, constrictive bronchiolitis, tuberculosis, and cystic fibrosis.

At least 24 hours after withdrawal of long-acting beta-2 agonists, short and long-acting anti-cholinergics, and slowrelease theophylline, in the absence of exacerbation in the preceding 12 weeks, the patients underwent both in baseline condition and 30 minutes after the inhalation of albuterol (400 mcg by metered-dose inhaler plus spacer) pulmonary function tests (spirometry, maximal flow/volume curve, lung volumes by $\mathrm{N}_{2}$-multibreath wash-out test) (System 1070, Medical Graphics, St Paul, MN, USA), determination of mouth pressure 100 milliseconds after the beginning of quiet inspiration during airways occlusion $\left(\mathrm{P}_{0.1}\right)$ performed at EELV, and measurements of maximal inspiratory pressure (MIP) at EELV during a Muller maneuver (Resp Mech module, Medical Graphics, St Paul, MN, USA). Both $\mathrm{P}_{0.1}$ and MIP were obtained in triplicate with adequate time intervals among the different measurements and the values used for analysis were the average of the two highest ones. Subsequently, the patients were classified, according to the IC changes after acutely inhaled albuterol, in volume nonresponders (increase of $\mathrm{IC}<12 \%$ and $200 \mathrm{~mL}$ of baseline: group 1) and volume responders (increase of IC $\geq 12 \%$ and $200 \mathrm{~mL}$ of baseline: group 2).

All spirometric parameters were analyzed as percent of predicted values. ${ }^{10}$ The IC predicted values were those proposed by Tantucci et al. ${ }^{11}$ Predicted values of IC for those patients aged less than 65 were obtained by backextrapolating the reference equations. The patients were recruited and tested if able to correctly perform the pulmonary function tests according to the American Thoracic Society guidelines. ${ }^{12}$ The study was approved by the Ethics Committee of the Hospital "Spedali Civili" of Brescia and each patient signed an informed consent for collection and treatment of data.

\section{Statistical analysis}

Differences between groups were assessed according to an unpaired nonparametric test (Mann-Whitney test) while comparisons of functional parameters before and after albuterol within groups were performed by a paired nonparametric test (Wilcoxon test). The Pearson's linear correlations were used to establish association between the variables of interest and the determination coefficients were also given. A $P$-value less than 0.05 was considered as statistically significant. The calculations were made using the SPSS 14.0 statistical package (IBM Corporation, Armonk, NY, USA). Data were expressed as mean \pm standard deviation.

\section{Results}

Twenty-two COPD patients (18 male) with a mean age of $72 \pm 6$ years and $\mathrm{FEV}_{1}$ equal to $0.78 \pm 0.26 \mathrm{~L}(33 \% \pm 11 \%$ predicted) were studied. Their anthropometric and functional characteristics are shown in Table 1. At baseline, a severe reduction of $\mathrm{FEV}_{1}$ with a marked increase of residual volume and functional residual capacity and reduction of IC were observed in these patients who exhibited, as expected, high values of $\mathrm{P}_{0.1}$.

No significant differences, however, were found at rest for spirometric parameters, lung volumes, neuromuscular drive, and maximal isometric force of inspiratory muscles between volume non-responders (group 1: increase of IC $<12 \%$ and $200 \mathrm{~mL}$ of baseline) and volume responders (group 2: increase of IC $\geq 12 \%$ and $200 \mathrm{~mL}$ of baseline) (Table 1).

Following inhalation of albuterol, $\mathrm{FEV}_{1}$ increased by $50 \pm 50 \mathrm{~mL}$ (from $0.87 \pm 0.25 \mathrm{~L}$ to $0.92 \pm 0.22 \mathrm{~L}$ ) in group 1 and by $130 \pm 70 \mathrm{~mL}$ (from $0.74 \pm 0.27 \mathrm{~L}$ to $0.87 \pm 0.28 \mathrm{~L}$ ) in group 2 .

$\mathrm{P}_{0.1}$, MIP, and their ratio $\left(\mathrm{P}_{0.1} / \mathrm{MIP} \%\right)$ are displayed in Table 2, before and after albuterol for all patients and those 
Table I Anthropometric and functional characteristics observed in all patients and two groups of them, divided according to the absence $(n=7)$ or presence $(n=15)$ of significant change of IC (>I $2 \%$ from baseline and $200 \mathrm{~mL})$ after acute bronchodilator at rest

\begin{tabular}{|c|c|c|c|c|}
\hline $\mathrm{n}$ & 22 & 7 & 15 & \\
\hline Age (year) & $68 \pm 8$ & $7 I \pm 6$ & $66 \pm 10$ & ns \\
\hline Gender (M/F) & $18 / 4$ & $7 / 0$ & $\mathrm{II} / 4$ & I \\
\hline $\begin{array}{l}\text { Smoke exposure } \\
\text { (pack years) }\end{array}$ & $45 \pm 22$ & $43 \pm 20$ & $46 \pm 23$ & ns \\
\hline SVC (\% pred) & $78 \pm 20$ & $77 \pm 23$ & $79 \pm 20$ & ns \\
\hline $\mathrm{FEV}_{1}$ (\% pred) & $33 \pm 10$ & $33 \pm 9$ & $33 \pm 11$ & ns \\
\hline FVC (\% pred) & $74 \pm 19$ & $73 \pm 20$ & $74 \pm 19$ & ns \\
\hline $\mathrm{FEV}_{1} / \mathrm{FVC} \%$ & $35 \pm 9$ & $36 \pm 12$ & $34 \pm 7$ & ns \\
\hline IC (\% pred) & $55 \pm 18$ & $59 \pm 27$ & $54 \pm 14$ & ns \\
\hline RV (\% pred) & $190 \pm 63$ & $183 \pm 60$ & $193 \pm 67$ & ns \\
\hline TLC (\% pred) & $|2| \pm 24$ & $115 \pm 23$ & $124 \pm 25$ & ns \\
\hline $\mathrm{P}_{0.1}\left(\mathrm{~cm} \mathrm{H}_{2} \mathrm{O}\right)$ & $4.7 \pm 1.2$ & $4.2 \pm 0.5$ & $4.9 \pm 1.4$ & ns \\
\hline MIP $\left(\mathrm{cm} \mathrm{H}_{2} \mathrm{O}\right)$ & $69 \pm 19$ & $78 \pm 20$ & $65 \pm 18$ & ns \\
\hline $\mathrm{PaO}_{2}(\mathrm{mmHg})$ & $66 \pm 10$ & $64 \pm 7$ & $67 \pm 11$ & ns \\
\hline $\mathrm{PaCO}_{2}(\mathrm{mmHg})$ & $44 \pm 5$ & $42 \pm 7$ & $45 \pm 6$ & ns \\
\hline
\end{tabular}

Note: Data are mean \pm SD.

Abbreviations: IC, inspiratory capacity; SVC, slow vital capacity; $\mathrm{FEV}_{1}$, forced expiratory volume in I second; FVC, forced vital capacity; RV, residual volume; TLC, total lung capacity; $P_{0.1}$, mouth pressure 100 milliseconds after the beginning of quiet inspiration during airways occlusion; MIP, maximal inspiratory pressure; SD, standard deviation.

with and without significant increase of IC (as a percentage of baseline).

Despite the reduction of EELV as reflected by the increase of IC, $\mathrm{P}_{0.1}$ was significantly reduced in volume responder COPD patients $(P<0.001)$. Since MIP values increased with decreasing EELV, $\mathrm{P}_{0.1} / \mathrm{MIP} \%$ was markedly decreased in volume responder COPD patients after albuterol. In contrast, marginal changes in $\mathrm{P}_{0.1}$ and no changes in MIP and $\mathrm{P}_{0.1} / \mathrm{MIP} \%$ were observed in volume non-responder COPD patients after bronchodilator.

Changes in IC (as a percentage of baseline) and $\mathrm{P}_{0.1}$ following acute administration of albuterol are plotted in Figure 1, panel A, showing a close direct correlation between reduction of DH (as reflected by the IC increase) and decreased neuromuscular drive at rest $\left(r^{2}=0.59 ; P<0.01\right)$. A similar relationship was found between changes in IC (as a percentage of baseline) and $\mathrm{P}_{0.1} / \mathrm{MIP} \%$ ratio, as shown in Figure 1, panel B $\left(r^{2}=0.56 ; P<0.01\right)$. No variations of the breathing pattern parameters such as tidal volume $(\mathrm{Vt})$, respiratory rate (RR), inspiratory (Ti) and expiratory time (Te), mean inspiratory flow (VT/Ti), and duty cycle (Ti/Ttot) were observed before and after albuterol administration in both groups of COPD patients.

\section{Discussion}

The results of this study indicate that in stable COPD patients at rest the neuromuscular output to inspiratory muscles is related to the degree of pulmonary hyperinflation and the reduction of $\mathrm{DH}$ possibly achieved by bronchodilator induces a significant decrease of inspiratory drive. Since bronchodilators have been shown to limit exertional and chronic dyspnea in COPD mainly by decreasing $\mathrm{DH}$, our findings suggest that this may occur partly because of reduction on central motor output to inspiratory muscles.

It has been demonstrated that COPD patients have a high neural drive even at rest, as reflected by the increased baseline $\mathrm{P}_{0.1} \cdot{ }^{5}$ Many factors have been implicated to explain this elevated motor command to inspiratory muscles. Included among them are increased airflow resistance, abnormal gas exchange, weak respiratory muscles, and high ventilatory requirements. $^{13}$

Much evidence has been collected showing that distressing breathlessness in moderate-to-severe COPD patients is mostly linked to the occurrence of $\mathrm{DH} .{ }^{3}$ The imbalance between the volume displacement and the muscular effort required to achieve it, known as neuromechanical or neuroventilatory dissociation, is thought to be the main mechanism by which DH causes chronic and exertional dyspnea in COPD. ${ }^{9}$ Other mechanisms, however, have been invoked in COPD patients as able to generate dyspnea and

Table 2 Resting values of IC and $\mathrm{P}_{0.1}$, MIP, and their ratio before (Pre-Br) and after (Post-Br) acute administration of bronchodilator

\begin{tabular}{|c|c|c|c|c|c|c|}
\hline & \multicolumn{2}{|c|}{$\Delta \mathrm{IC}<\mathrm{I} 2 \%$ bas } & \multirow[t]{2}{*}{$P$} & \multicolumn{2}{|c|}{$\Delta \mathrm{IC}>\mathrm{I} 2 \%$ bas } & \multirow[t]{2}{*}{$P$} \\
\hline & Pre-Br & Post-Br & & Pre-Br & Post-Br & \\
\hline$n$ & 7 & 7 & & 15 & 15 & \\
\hline IC (L) & $1.77 \pm 0.45$ & $1.88 \pm 0.48$ & $<0.05$ & $1.30 \pm 0.46$ & $1.66 \pm 0.49$ & $<0.001$ \\
\hline$\Delta \mathrm{IC}$ (\% bas) & & $6 \pm 4$ & & & $30 \pm 13$ & \\
\hline $\mathrm{P}_{0.1}\left(\mathrm{~cm} \mathrm{H} \mathrm{H}_{2} \mathrm{O}\right)$ & $4.2 \pm 0.5$ & $4.0 \pm 0.6$ & $<0.05$ & $4.9 \pm 1.4$ & $3.8 \pm 1.4$ & $<0.001$ \\
\hline $\mathrm{MIP}\left(\mathrm{cm} \mathrm{H} \mathrm{H}_{2} \mathrm{O}\right)$ & $78 \pm 20$ & $79 \pm 20$ & ns & $65 \pm 18$ & $70 \pm 20$ & $<0.01$ \\
\hline $\mathrm{P}_{0.1} / \mathrm{MIP} \%$ & $5.5 \pm 1.1$ & $5.1 \pm 1.1$ & ns & $8.2 \pm 3.0$ & $5.8 \pm 2.0$ & $<0.01$ \\
\hline
\end{tabular}

Notes: Clinically significant improvement of $P_{0.1}$ and MIP and $P_{0.1} /$ MIP ratio were observed only in COPD patients with significant increase in IC. Data are mean \pm SD. Abbreviations: IC, inspiratory capacity; $\mathrm{P}_{0.1}$, mouth pressure 100 millseconds after the beginning of quiet inspiration during airways occlusion; MIP, maximal inspiratory pressure; COPD, chronic obstructive pulmonary disease; Pre-Br, pre-bronchodilator; Post-Br, post-bronchodilator; bas, baseline; SD, standard deviation. 
A

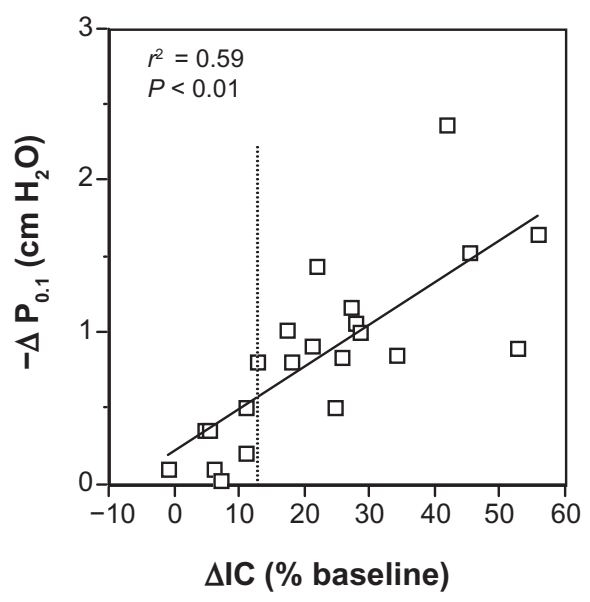

B

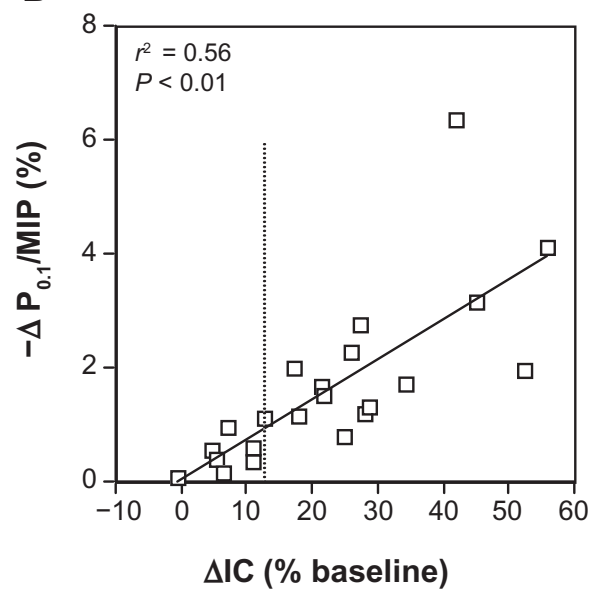

Figure I Relationship between changes in IC and $\mathrm{P}_{0.1}(\mathbf{A})$ and $\mathrm{P}_{0.1} / \mathrm{MIP} \%(\mathbf{B})$, following bronchodilator in groups of stable severe-to-very severe COPD patients at rest. Note: The vertical lines indicate the threshold of a significant increase in IC.

Abbreviations: IC, inspiratory capacity; $\mathrm{P}_{0.1}$, mouth pressure 100 millseconds after the beginning of quiet inspiration during airways occlusion; MIP, maximal inspiratory pressure; COPD, chronic obstructive pulmonary disease.

particularly an increased sense of work/effort following stimuli such as increased ventilatory requirements, elevated EELV, and a related increase in elastic inspiratory threshold load due to intrinsic positive end-expiratory pressure. ${ }^{3,9,14}$ A high inspiratory neural drive, especially in the presence of functionally or intrinsically weakened inspiratory muscles is in fact associated with a greater respiratory effort. ${ }^{15}$

The neural pathways underlying the sense of work/effort include corollary discharge from motor cortical and bulbar centers ${ }^{16}$ and possibly multiple afferences from mechanical and metabolic receptors of respiratory and skeletal muscles to the sensory cortex that are believed to contribute to the dyspnea sensation. ${ }^{13}$

In our work we showed a clear link between neuromuscular output level and severity of DH at rest in stable COPD patients and the possibility of significantly reducing it when an effective desufflation is achievable, in this case after acute bronchodilator inhalation, as indicated by a marked IC increase.

The effect on the reduction of respiratory drive observed in COPD patients who significantly increase IC after bronchodilator is likely even greater than we have shown, given the corresponding reduction in EELV that per se should increase, not decrease $P_{0.1}$ because of better force-length relationship of the inspiratory muscles. In fact, although we did not measure directly EELV, with the reasonable assumption that total lung capacity remains unchanged after acute inhalation of albuterol, the IC variation specularly reflects the EELV change.
Therefore, the decrease of neuromuscular output at rest in COPD patients after bronchodilating drugs may reflect an effective desufflation in the absence of important $\mathrm{FEV}_{1}$ change also when the lung volumes and IC measurements cannot be adequately performed.

Drugs or non-pharmacological interventions that are effective in decreasing DH may diminish both the degree of neuromuscular uncoupling and the amount of neuromuscular drive. It is conceivable that either mechanism can contribute to reduce chronic and exertional dyspnea in COPD.

Finally, our results could be useful to explain the wide range of resting values of $\mathrm{P}_{0.1}$ observed in COPD patients with apparently similar severity of airflow obstruction, as measured by spirometry, taking into account the possible effect of different degrees of pulmonary hyperinflation.

Some limits of the study need to be addressed. The amount of neural drive is indirectly assessed by the $\mathrm{P}_{0.1}$ measurement at the mouth. The dynamically hyperinflated COPD patients have some intrinsic positive end-expiratory pressure. Thus, changes of esophageal $\mathrm{P}_{0.1}$ (that truly reflect the neuromuscular output) occur before those of mouth $\mathrm{P}_{0.1}$ and the two measurements correspond only when the initial pressure decay is linear, as it usually is. The inspiratory muscles in COPD can be intrinsically weak (myopathy, sarcopenia, etc) and $\mathrm{P}_{0.1}$ could be influenced by the force developed at the beginning of inspiration, without carefully reflecting the central neural drive. However, this seems unlikely because early (the first 100 milliseconds) contraction of inspiratory muscles is not impaired under these circumstances, as found in several neuromuscular diseases. ${ }^{17,18}$ 
Although baseline parameters were not significantly different between volume and non-volume responders, the first group tends to be younger with more females, showing slightly higher $\mathrm{P}_{0.1}$ and lower MIP. Since the sample size is small, we cannot exclude that these differences could be relevant when larger cohorts are examined.

In conclusion, a large $\mathrm{P}_{0.1}$ decrease, MIP increase, and reduction of the $\mathrm{P}_{0.1} / \mathrm{MIP}$ ratio were found after bronchodilator only in COPD patients with a marked IC increase. More interestingly, the improvement of $\mathrm{DH}$ and the decrease in neuromuscular drive were closely related. These findings indicate that decreasing $\mathrm{DH}$ by bronchodilators is associated with a reduction of the central neuromuscular drive and effort/work related sensation, suggesting that corollary discharge linked to an augmented central inspiratory output is an adjunctive mechanism promoting dyspnea in COPD patients with dynamic hyperinflation.

\section{Disclosure}

The authors report no conflicts of interest in this work.

\section{References}

1. Eltayara L, Becklake MR, Volta CA, Milic-Emili J. Relationship between chronic dyspnea and expiratory flow limitation in patients with chronic obstructive pulmonary disease. Am J Respir Crit Care Med. 1996;154(6 Pt 1):1726-1734.

2. O'Donnell DE. Breathlessness in patients with chronic airflow limitation. Mechanisms and management. Chest. 1994;106(3):904-912.

3. O'Donnell DE, Revill SM, Webb KA. Dynamic hyperinflation and exercise intolerance in chronic obstructive pulmonary disease. $\mathrm{Am} \mathrm{J}$ Respir Crit Care Med. 2001;164(5):770-777.

4. Diaz O, Villafranca C, Ghezzo H, et al. Role of inspiratory capacity on exercise tolerance in COPD patients with and without expiratory flow limitation at rest. Eur Respir J. 2000;16(2):269-275.
5. Sorli J, Grassino A, Lorange G, Milic-Emili J. Control of breathing in patients with chronic obstructive lung disease. Clin Sci Mol Med. 1978;54(3):295-304.

6. Tantucci C, Duguet A, Similowki T, Zelter M, Derenne JP, Milic Emili J. Effect of salbutamol on dynamic hyperinflation in chronic obstructive pulmonary disease patients. Eur Respir J. 1998;12(4): 799-804.

7. Boni E, Corda L, Franchini D, et al. Volume effectand exertional dyspnea after bronchodilator in patients with COPD with and without expiratory flow limitation at rest. Thorax. 2002;57(6):528-532.

8. O'Donnell DE, Voduc N, Fitzpatrick M, Webb KA. Effect of salmeterol on the ventilatory response to exercise in chronic obstructive pulmonary disease. Eur Respir J. 2004;24(1):86-94.

9. O'Donnell DE, Webb KA. Exertional breathlessness in patients with chronic airflow limitation. The role of lung hyperinflation. Am Rev Respir Dis. 1993;148(5):1351-1357.

10. [No authors listed]. Standardized lung function testing. Report working party. Bull Eur Physiopathol Respir. 1983;19 Suppl 5:1-95.

11. Tantucci C, Pinelli V, Cossi S, et al. Reference values and repeatability of inspiratory capacity for men and women aged 65-85. Resp Med. 2006;100(5):871-877.

12. [No authors listed]. Lung function testing: selection of reference values and interpretative strategies. American Thoracic Society. Am Rev Respir Dis. 1991;144(5):1202-1218.

13. Manning HL, Schwartzstein RM. Pathophysiology of dyspnea. New Engl J Med. 1995;333:1547-1553.

14. Yan S. Sensation of inspiratory difficulty during inspiratory threshold and hyperinflationary loadings. Effect of inspiratory muscle strength. Am J Respir Crit Care Med. 1999;160(5 Pt 1):1544-1549.

15. O'Connell JM, Campbell AH. Respiratory mechanics in airways obstruction associated with inspiratory dyspnea. Thorax. 1976;31(6): 669-677.

16. McCloskey DI. Corollary discharges: motor commands and perception. In: Brookhart JM, Mountcastle VB, editors. Handbook of Physiology Section 1 the Nervous System Volume I Cellular Biology of Neurons, Part 2. Bethesda: American Physiology Society; 1981: 1415-1417.

17. Bégin R, Bureau MA, Lupien L, Lumieux B. Control of breathing in Duchenne's muscular dystrophy. Am J Med. 1980;69(2):227-234.

18. Tantucci C, Massucci M, Piperno R, Betti L, Grassi V, Sorbini CA. Control of breathing and respiratory muscle strength in patients with multiple sclerosis. Chest. 1994;105(4):1163-1170.
International Journal of COPD

\section{Publish your work in this journal}

The International Journal of COPD is an international, peer-reviewed journal of therapeutics and pharmacology focusing on concise rapid reporting of clinical studies and reviews in COPD. Special focus is given to the pathophysiological processes underlying the disease, intervention programs, patient focused education, and self management protocols.

\section{Dovepress}

This journal is indexed on PubMed Central, MedLine and CAS. The manuscript management system is completely online and includes a very quick and fair peer-review system, which is all easy to use. Visit $\mathrm{http}: / / \mathrm{www}$.dovepress.com/testimonials.php to read real quotes from published authors. 